\title{
The Effectiveness of BIPA Learning at Students of Indonesian Concentration Department, Fatoni University, Thailand
}

\author{
Mr. Ku-Ares Tawandorloh ${ }^{1}$ \& Islahuddin $^{2}$ \\ ${ }^{12}$ Fatoni University, Thailand \\ kumukhlish-tei@hotmail.com ${ }^{1}$, islahuddin.ma@gmail.com ${ }^{2}$
}

\begin{abstract}
This study aims to describe the effectiveness of learning Indonesian for Foreign Speakers (BIPA) at students of Indonesian Concentration Department, Fatoni University. The subjects of the study were the students of Indonesian Concentration Department. The data of this research were collected through questionnaire and test. The results showed that BIPA learning could be more effective in learning Indonesian in general. This could be proven from the questionnaire and tests taken by the students in which on speaking tests, students were better in communicating Indonesian; and in reading test, the students show increasingly in understanding text. The students also showed more capability in the making paragraph on the writing test as well as in listening test in which the students were able to understand fully what were said on the test. The research also noted that both students of Malay and Thai mother tongue /first language had better ability of those four skills of Indonesian. Meanwhile, the students who used to lived in Indonesia and Malaysia showed excellent skill in speaking and reading, while in writing and listening skill were categorised good.
\end{abstract}

Keywords: effectiveness, learning, BIPA, Fatoni University

\section{PENDAHULUAN}

Ki Hadjar Dewantara salah satu tokoh pendidikan asal Perguruan Tamansiswa, Yogyakarta, mengungkapkan bahwa dasar bahasa Indonesia adalah bahasa Melayu. Bahasa melayu tersebut disesuaikan dengan pertumbuhannya dalam masyarakat Indonesia. Sehingga bahasa Indonesia berkembang seirama dengan perkembangan masyarakat Indonesia [1]. Seiring dengan perkembangan zaman, Bahasa Indonesia menjadi bahasa internasional. Dengan terbitnya Undang-undang Nomor 24 tahun 2009 tentang Bendera, Bahasa dan Lambang Negara semakin mendukung fungsi bahasa Indonesia sebagai bahasa Internasional.

Bahasa Indonesia mengalami perkembangan yang sangat pesat, tidak hanya di Indonesia tetapi juga di luar negeri. Terbukti banyak penutur asing berminat mempelajari bahasa Indonesia atau yang sering disebut BIPA. BIPA akronim dari Bahasa Indonesia bagi Penutur Asing adalah program pembelajaran bahasa Indonesia yang dikhususkan untuk warga negara asing [2]. Pembelajaran bahasa Indonesia dilakukan bukan hanya di Indonesia saja, melainkan dilakukan di luar negeri. Salah satu negara di Kawasan ASEAN yang menyelenggarakan pembelajaran BIPA adalah negara Thailand. Terdapat beberapa universitas yang telah menyelenggarakan pembelajaran BIPA, baik sebagai mata kuliah regional studies yang 
diajarkan oleh dosen dari Thailand misalnya pada Universitas Maejo, maupun sebagai mata kuliah pilihan yang diajarkan oleh dosen dari Indonesia, di antaranya Universitas Tammasat, Universitas Naraesuan, Universitas Prince of Songkhla, dan universitas yang lain.

Selain itu, pada 2016, pembelajaran BIPA telah diselenggarakan di Universitas Fatoni. Pembelajaran BIPA didesain sebagai pengantar bagi para mahasiswa dalam memahami bahasa, sastra, dan budaya Indonesia. Pembelajaran BIPA telah berlangsung selama empat tahun, merupakan salah satu mata kuliah berjumlah 3 sks, diajarkan pada semester I, dan berada di dalam kurikulum Konsentrasi Bahasa Indonesia, Fakultas Ilmu Budaya dan Ilmu Sosial, Universitas Fatoni, Thailand.

Meskipun telah berlangsung selama empat tahun, tetapi penelitian pembelajaran BIPA di Universitas Fatoni, belum pernah dilakukan. Oleh karena itu, efektifitas pembelajaran BIPA bagi mahasiswa Konsentrasi Bahasa Indonesia pun belum terjawab. Efektifitas pembelajaran BIPA mengacu pada dampak pembelajaran BIPA terhadap empat aspek kebahasaan, di antaranya berbicara, membaca, menulis, dan menyimak. Adapun rumusan masalah pada penelitian ini adalah bagaimanakan efektifitas pembelajaran BIPA bagi mahasiswa Konsentrasi Bahasa Indonesia, Universitas Fatoni?

\section{METODE PENELITIAN}

Penelitian ini dilakukan dengan menggunakan metode kualitatif. Adapun metode kualitatif dapat diartikan sebagai prosedur penelitian yang menghasilkan data deskriptif berupa katakata tertulis atau lisan dari orang-orang dan perilaku yang diamati [3]. Penelitian ini didasarkan pada asumsi seberapa jauh efektifitas pembelajaran BIPA bagi para mahasiswa Konsentrasi Bahasa Indonesia, Universitas Fatoni. Instrumen penelitian adalah peneliti sendiri. Lokasi penelitian ini adalah di Universitas Fatoni tahun 2019. Sampel penelitian diambil dengan cara random sampling. Pengumpulan data dilakukan dengan pengisian angket dan tes. Data penelitian berupa data kualitatif berupa catatan, jawaban, dan saran yang diperoleh secara tertulis dan lisan dalam angket dan tes yang diberikan. Selanjutnya, teknik analisis data yang digunakan dalam penelitian ini adalah teknik deskriptif kualitatif. Data-data yang terkumpul, dikategorikan dan dilakukan analisis dengan cara mengidentifikasi data yang menunjukkan hubungan kesesuaian dengan penelitian. Setelah itu, data disajikan dengan teknik deskriptif.

\section{HASIL DAN PEMBAHASAN}

Pembelajaran BIPA di Universitas Fatoni, bukan hanya berada di dalam kelas, tetapi dilakukan juga di luar kelas, di antaranya kunjungan ke Konsulat Republik Songkhla, berkomunikasi langsung dengan para mahasiswa Indonesia yang sedang menempuh pendidikan di Universitas Fatoni dan kegiatan bulanan atas kerja sama mahasiswa dengan jurusan, yaitu Seminar Kemahiran Berbahasa Melayu/Indonesia. Hal itu dilakukan agar para mahasiswa lebih efektif dalam penguasaan bahasa, sastra, dan budaya Indonesia. Selain itu, pembelajaran BIPA pada Konsentrasi Bahasa Indonesia, diikuti oleh berbagai latar belakang keluarga, di antaranya: 1) mahasiswa berbahasa ibunda bahasa Melayu; 2) mahasiswa berbahasa ibunda bahasa Thai; 3) mahasiswa yang pernah tinggal di Indonesia/Malaysia selama lebih dari setahun; dan 4) mahasiswa yang tidak pernah tinggal di Indonesia/Malaysia. 


\subsection{Keterampilan Berbahasa}

Pembelajaran BIPA mencakup empat keterampilan berbahasa. Keempat kemampuan berbahasa tersebut, yaitu keterampilan menyimak (listening skill), keterampilan berbicara (speaking skill), keterampilan membaca (reading skill), dan keterampilan menulis (writing skill) [4]. Hasil penelitian menunjukkan bahwa efektifitas pembelajaran BIPA secara umum dapat meningkatkan keterampilan berbahasa mahasiswa. Keterampilan berbicara mendapatkan skor rata-rata sebesar 20,54, skor tersebut termasuk kategori baik. Keterampilan membaca mendapatkan skor rata-rata 12,36, skor tersebut termasuk kategori baik. Keterampilan menulis mendapatkan skor rata-rata 15,63, skor termasuk kategori baik. Keterampilan menyimak mendapat skor rata-rata 15,72, skor tersebut termasuk dalam kategori baik.

\subsection{Keterampilan Berbicara}

Komunikasi yang umum dan efektif dilakukan adalah berbicara. Berbicara merupakan kegiatan berbahasa yang aktif dari seorang pemakai bahasa [5]. Berbicara dapat dalam bentuk tindak tutur yang berupa bunyi-bunyi yang dihasilkan oleh alat ucap disertai dengan gerakgerik tubuh dan ekspesi raut muka. Berbicara merupakan media yang digunakan manusia untuk berkomunikasi [6]. Pada pembelajaran BIPA, keterampilan berbicara, terbagi menjadi dua bagian, yaitu monolog dan dialog. Pada bagian monolog, pemelajar mempraktikkan monolog pada saat bercerita ataupun mempraktikkan monolog dalam buku ajar, dan dosen segera membetulkan jika terdapat kesalahan. Adapun pada bagian dialog, pemelajar menghafal dialog di rumah, lalu mempraktikkan dialog antar sesama mahasiswa [7].

Berdasarkan hasil penelitian, secara umum pembelajaran BIPA dalam keterampilan berbicara dapat meningkatkan kemampuan mahasiswa dalam berkomunikasi dengan baik, di antaranya: 1) kemampuan berbicara; 2) kemampuan mengucapkan kata dengan lafal yang benar; 3) pembendaharaan kata; 4) berekspresi lebih baik saat berbicara; dan 5) mahasiswa mengucapkan kata dengan intonasi yang benar.

\subsection{Keterampilan Membaca}

Membaca merupakan suatu proses yang dilakukan oleh pembaca untuk memperoleh pesan yang disampaikan penulis melalui media bahasa tulis [8]. Keterampilan membaca berfokus pada keterampilan membaca sebuah teks atau bacaan. Keterampilan membaca, terbagi menjadi keterampilan membaca nyaring dan keterampilan membaca senyap. Membaca nyaring dilakukan untuk memahami informasi, pikiran, dan perasaan pengarang [8]. Pada pembelajaran BIPA, membaca nyaring bertujuan agar mahasiswa mampu melafalkan kata demi kata dalam bahasa Indonesia dengan baik dan benar. Adapun membaca senyap dilakukan dengan pemanfaatan mata dan ingatan. Pembacaan senyap pada pembelajaran BIPA dimaksudkan agar para mahasiswa mampu memahami makna dalam sebuah teks sederhana.

Berdasarkan hasil penelitian, secara umum pembelajaran BIPA dalam keterampilan membaca dapat meningkatkan keterampilan mahasiswa dalam memahami isi teks dan bacaan dengan baik, di antaranya: 1) melafalkan kata dengan benar; 2) membaca sesuai dengan intonasi; dan 3) menghayati suatu bacaan.

\subsection{Keterampilan Menulis}


Keterampilan menulis merupakan keterampilan menggunakan ejaan, tanda baca, pembentukan kata, penggunaan kalimat, pemilihan kalimat, pemilihan kata pengefektifan kalimat, membahasakan pikiran dengan cermat, tepat, logis, dan konsisten [9]. Pada pembelajaran BIPA, kemampuan menulis difokuskan pada penguasaan ejaan dan kemampuan menulis karangan. Penguasaan ejaan dimaksudkan agar para mahasiswa mampu menggunakan ejaan dengan baik dan benar, sedangkan kemampuan menulis karangan diharapkan mahasiswa mampu menulis karangan secara padu dan berkesinambungan.

Berdasarkan hasil penelitian, secara umum pembelajaran BIPA dalam keterampilan menulis dapat meningkatkan kemampuan dan membantu mahasiswa dalam mengarang atau membuat paragraf dengan baik, di antaranya: 1) menulis sesuai EYD, kosakata, ejaan, dan struktur kalimat; 2) pemilihan kosakata yang baik dalam penulisan; 3) menulis ejaan yang benar, dan 4) menulis dengan struktur kalimat yang benar.

\subsection{Keterampilan Menyimak}

Keterampilan menyimak yang merupakan "suatu proses yang mencakup kegiatan mendengarkan bunyi bahasa, mengidentifikasi, menginterpretasi, menilai, dan mereaksi atas makna yang terkandung di dalamnya [10] [11]. Kemampuan menyimak pada pembelajaran BIPA difokuskan pada penguasaan simakan. Kemampuan menyimak terbagi menjadi dua bagian, yaitu kemampuan menyimak sepintas lalu dan kemampuan menyimak mendalam.

Berdasarkan hasil penelitian, secara umum pembelajaran BIPA dalam keterampilan menyimak dapat meningkatkan kemampuan mahasiswa dalam memahami apa yang ada sepenuhnya dalam simakan dengan baik, di antaranya: 1) memahami lagu Indonesia; 2) memahami cerita pendek; 3) memahami berita singkat; dan 4) memahami suatu artikel.

\subsection{Latar Belakang Mahasiswa}

Pembelajaran BIPA diikuti oleh pemelajar dari berbagai latar belakang keluarga. Hasil penelitian menunjukkan efektifitas secara umum pembelajaran BIPA dapat diikuti dari berbagai latar belakang keluarga seperti berikut:

\section{a. Mahasiswa Berbahasa Ibunda Bahasa Melayu}

Berdasarkan lembar angket yang diisi oleh mahasiswa yang memiliki berbahasa ibunda Bahasa Melayu. Setelah pembelajaran BIPA terdapat data keterampilan berbahasa sebagai berikut: 1) keterampilan membaca memiliki skor rata-rata 20,88, termasuk kategori baik; 2) keterampilan membaca memperoleh skor rata-rata 12,44, termasuk kategori baik; 3) keterampilan menulis memperoleh skor rata-rata 15,78, termasuk kategori baik; dan 4) keterampilan menyimak memperoleh skor rata-rata 15,78 termasuk kategori baik.

Berdasarkan hasil penelitian di atas, dapat disimpulkan bahwa secara umum pembelajaran BIPA bagi mahasiswa berbahasa ibunda bahasa Melayu dapat meningkatkan kemampuan berbahasa dan berkategori baik.

\section{b. Mahasiswa berbahasa ibunda bahasa Thai}

Berdasarkan pengisisan lembar angket oleh mahasiswa berbahasa ibunda Bahasa Thai, dalam permbelajaran BIPA terdapat data keterampilan berbahasa sebagai berikut: 1) keterampilan membaca memiliki skor rata-rata 19, termasuk kategori baik; 2) keterampilan membaca memperoleh skor rata-rata 12 , termasuk kategori baik; 3) keterampilan menulis memperoleh skor rata-rata 15, termasuk kategori baik; dan 4) keterampilan menyimak memperoleh skor rata-rata 15,5 , termasuk kategori baik. 
Berdasarkan hasil penelitian di atas, dapat disimpulkan bahwa secara umum pembelajaran BIPA bagi mahasiswa berbahasa ibunda bahasa Thai dapat meningkatkan kemampuan berbahasa dan berkategori baik.

\section{c. Mahasiswa pernah tinggal di Indonesia/Malaysia}

Berdasarkan pengisisan lembar angket oleh mahasiswa yang pernah tinggal di Indonesia/Malaysia lebih dari setahun, dalam pembelajaran BIPA terdapat data keterampilan berbahasa sebagai berikut: 1) keterampilan membaca memperoleh skor rata-rata 23, termasuk kategori sangat baik; 2) keterampilan membaca memperoleh skor rata-rata 13,5, termasuk kategori sangat baik; 3) keterampilan menulis memperoleh skor rata-rata 16,5, termasuk kategori baik; dan 4) keterampilan menyimak memperoleh skor rata-rata 16,5, termasuk kategori baik.

Berdasarkan hasil penelitian di atas, dapat disimpulkan bahwa secara umum pembelajaran BIPA bagi mahasiswa yang pernah tinggal di Indonesia/Malaysia dapat meningkatkan kemampuan berbahasa dan untuk keterampilan berbicara dan membaca dalam kategori sangat baik, sedangkan untuk keterampilan menulis dan menyimak berkategori baik.

\section{d. Mahasiswa yang tidak pernah tinggal di Indonesia/Malaysia}

Berdasarkan pengisian lembar angket oleh mahasiswa yang belum pernah tinggal di Indonesia/Malaysia, dalam pembelajaran BIPA terdapat data keterampilan berbahasa sebagai berikut: 1) keterampilan membaca memperoleh skor rata-rata 20, termasuk kategori baik; 2) keterampilan membaca memperoleh skor 12,1, termasuk kategori baik; 3) keterampilan menulis memperoleh 15,44, termasuk kategori baik; dan 4) keterampilan menyimak memperoleh skor rata-rata 15,56 , termasuk kategori baik.

Berdasarkan hasil penelitian di atas, dapat disimpulkan bahwa secara umum pembelajaran BIPA bagi mahasiswa yang belum pernah tinggal di Indonesia maupun Malaysia dapat meningkatkan kemampuan berbahasa dan berkategori baik [12].

\section{SIMPULAN}

Berdasarkan hasil penelitian di atas, dapat disimpulkan bahwa efektifitas pembelajaran BIPA bagi mahasiswa Konsentrasi Bahasa Indonesia dapat menambah keterampilan berbahasa. Pada keterampilan berbicara, mahasiswa lebih mampu berkomunikasi. Pada keterampilan membaca, mahasiswa lebih mampu memahami isi teks bacaan. Pada keterampilan menulis, mahasiswa sudah mampu mengarang/membuat paragraf. Pada keterampilan menyimak, mahasiswa sudah sepenuhnya memahami apa yang ada dalam simakan.

Selain itu, hasil penelitian menunjukkan bahwa baik mahasiswa berbahasa ibunda bahasa Thai maupun bahasa Melayu berkemampuan baik untuk semua keterampilan. Adapun bagi mahasiswa yang pernah tinggal di Indonesia/Malaysia selama lebih dari setahun memiliki keterampilan berbicara dan membaca sangat baik, sedangkan keterampilan menulis dan menyimak baik.

\section{REFERENCES}

[1] S. Sudaryanto, "Tiga Fase Perkembangan Bahasa Indonesia (1928-2009): Kajian Linguistik Historis," Aksis J. Pendidik. Bhs. dan Sastra Indones., vol. 2, no. 1, pp. 116, 2018.

[2] N. P. A. W. Sari, I. M. Sutama, and I. D. G. B. Utama, "Pembelajaran Bahasa Indonesia bagi Penutur Asing (BIPA) di Sekolah Cinta Bahasa, Ubud, Bali," J. 
Pendidik. Bhs. dan Sastra Indones. Undiksha, vol. 5, no. 3, 2016.

[3] L. J. Moleong, Metodologi Penelitian Kualitatif edisi Revisi. Bandung: PT. Remaja Rosda Karya, 2014.

[4] M. N. Wangid, "Peningkatan Keterampilan Menulis Menggunakan Pendekatan Proses dengan Media Gambar di SDN 3 Sakra," J. Prima Edukasia, vol. 2, no. 1, pp. 1-13, 2014.

[5] M. Abdurahman, "Pembelajaran Berbicara bagi Siswa dengan Hambatan Kecerdasan," JASSI ANAKKU, vol. 18, no. 1, pp. 62-69.

[6] A. Setyonegoro, "Hakikat, Alasan, dan Tujuan Berbicara (Dasar Pembangun Kemampuan Berbicara Mahasiswa)," Pena J. Pendidik. Bhs. dan Sastra, vol. 2, no. 2, 2013.

[7] S. Slamet, "Efektifitas Pembelajaran Keterampilan Speaking dengan Pendekatan Genre di Universitas Muhammadiyah Surakarta," J. Varia Pendidik., vol. 24, no. 1, pp. 54-57, 2012.

[8] T. G. Henry, "Membaca Sebagai Suatu Keterampilan Berbahasa," Bandung: Angkasa, 2008.

[9] L. O. R. Aljatila, "Meningkatkan Keterampilan Menulis Karangan Deskriptif melalui Model Kooperatif Tipe Round Table Pada Siswa Kelas X-1 SMAN Kulisusu Barat," Humanika, vol. 15, no. 3, pp. 1-14, 2015.

[10] T. Widianti, "Meningkatkan Keterampilan Menyimak Dengan Menerapkan Model Pembelajaran Quantum dalam Membuat Denah Berdasarkan Penjelaskan Yang Didengar (Penelitian Tindakan Kelas di Kelas IV SDN Sindang V Kecamatan Sumedang Utara Kabupaten Sumedang)." Universitas Pendidikan Indonesia, 2016.

[11] N. Resmini, T. Hartati, and I. Cahyani, "Pembinaan dan Pengembangan Pembelajaran Bahasa dan Sastra Indonesia,” Bandung: Percetakan Angkasa, 2009.

[12] K. Saddhono, "Integrating culture in Indonesian language learning for foreign speakers at Indonesian universities,” J. Lang. Lit., vol. 6, no. 2, 2015. 